\title{
INTERIORIDAD Y EXTERIORIDAD EN UNAMUNO
}

\author{
...la realidad es la intima. La realidad no la \\ constituyen las bambalinas, ni las decoraciones, \\ ni el traje, ni el paisaje... La realidad en la \\ vida de Don Quijote no fueron los molinos de \\ viento, sino los gigantes. Los molinos eran feno- \\ ménicos, aparenciales; los gigantes eran numé- \\ nicos, substanciales. (Tres novelas ejemplares $y$ \\ un prólogo, Prólogo).
}

"Molinos fenoménicos, gigantes numénicos": así, apoyándose en la terminología kantiana que usó a lo largo de toda su obra, presentaba Unamuno, una vez más en 1920 , la oposición entre el mundo de fuera y el mundo de dentro. Muchos años antes, Pachico Zabalbide, el personaje de Paz en la guerra, había descubierto "el alma de las cosas" 1 y desde entonces, ensayo tras ensayo, libro tras libro, Unamuno fué afirmando la dualidad vida interior-vida externa, númenofenómeno, que culmina poéticamente en sus nivolas cuando Unamuno escoge, al parecer para siempre, el mundo de dentro y rechaza lo aparencial externo. Así, especialmente desde En torno al casticismo $(1895)^{2}$, Unamuno penetra y aconseja penetrar la corteza de la realidad circunstancial para llegar hasta sus entrañas y, a ser posible, hasta sus "sotoentrañas".

Primera época: "En torno al casticismo"

En este sentido, es sorprendente la cantidad de expresiones "interiorizantes" que encontramos a lo largo de su obra. Si empezamos por En torno al casticismo, libro que ataca un problema histórico,

1 "Olvídase [Pachico] del curso fatal de las horas, y en un instante que no pasa, eterno, inmóvil, siente en la contemplación del inmenso panorama la hondura del mundo, la continuidad, la unidad, la resignación de sus miembros todos, y oye la canción silenciosa del alma de las cosas" (Paz en la guerra, 2 a ed., Madrid, 1923, pág. 333).

* Aunque los cinco ensayos de En torno al casticismo se escriben en 1895 y Paz en la guerra se publica en 1897 , considero la novela como antecedente de los ensayos porque el autor nos dice que en ella van encerrados más de doce años de trabajo (cf. prólogo a la 2 a ed.) y éstos son los años en que Unamuno, a raíz de su crisis racionalista de estudiante en Madrid, trata de recapturar el mundo 
temporal, y cuyo estilo es más bien superficial y didáctico ${ }^{3}$, el título del primero de los cinco ensayos de que se compone, La tradición eterna, nos indica ya que vamos a la búsqueda de algo más que una exposición didáctica de lo accidental histórico. Este título nos dice que Unamuno pretende acercarse a lo eterno de esa tradición que, por lo general, se concibe en el tiempo y para el tiempo; nos dice que vamos en busca de esa vaga realidad que llamamos lo eterno y que está más allá, o más acá, o dentro de las cosas y de los accidentes del tiempo. Pero el tono de disertación profesoral parece estorbar a Unamuno. Es como si no se decidiera a llegar hasta donde se encuentra lo buscado. En efecto, las primeras páginas, tan objetivas y frías, no son más que la introducción al tema de la interioridad. Pronto (Ensayos, I, pág. 12) trata Unamuno de dar con la palabra que defina lo esencial, lo eterno, eso que está más allá, o más acá, o dentro de las cosas. Viene hablando de la filosofía y la ciencia; busca la relación esencial entre ambas y va con cuidado encontrando y rechazando varias imágenes que expresen esta relación: dice primero que la filosofía lleva algo en sí "de pre-científico y de subcientífico, de sobrecientífico, como se quiera"; y en seguida, habiendo rodeado el tema, se sumerge en él y nos da la relación exacta: lo que lleva en sí la filosofía es, en realidad, algo de "intra-científico".

Ya tenemos la primera intuición de lo eterno que, como en la

de paz interior de su infancia. "Aquí está el eco, y acaso el perfume, de los más hondos recuerdos de mi vida", nos dice (ibid.). Como revelación de un mundo interior de paz y armonía juvenil, Paz en la guerra es anterior a la ideología interiorizante de En torno al casticismo.

${ }^{3}$ En este libro Unamuno apenas comienza su carrera de ensayista y está muy lejos de su madurez de pensamiento y estilo. Las primeras palabras del libro nos recuerdan las definiciones de diccionario: "Castizo deriva de casta, así como casta deriva del adjetivo casto, puro. Se aplica de ordinario el vocablo casta a las razas o variedades puras de especies animales, sobre todo domésticas..." Cuando mucho, Unamuno está haciendo una exposición etimológica superficial, que más nos recuerda a los personajes burlescos de sus novelas (Don Avito de Amory pedagogia, por ejemplo) que a Unamuno mismo. El tono general de estos ensayos nos dice a las claras que habla el profesor, el joven profesor que cxponc con "objetividad" científica una doctrina o teoría histórica; este frío pedagogismo está muy lejos de la contemplación cálida y luminosa del final de Paz en la guerra o del extraordinario "egoísmo" que es el eje del estilo de Unamuno en la Vida de Don Quijote y Sancho o en Del sentimiento trágico. A primera vista, más parece que, en esta obra, Unamuno recorre caminos ajenos al alma descubierta en la intuición de su primera novela. Veamos un corto ejemplo más, algunas palabras del segundo apartado del segundo de los cinco ensayos del libro: "Ocupada gran parte de España por la morisma durante la Edad Media, y fraccionado ẹl resto en multitud de estadillos, fué en ella acentuándose la corriente contral a medida que se acercaba la Edad Moderna..." (Ensayos, Aguilar, Madrid, 1942, vol. I, pág. 35); y así muchas páginas de exposición histórica y objetiva a lo largo de la obra. 
revelación casi mística de las últimas páginas de Paz en la guerra ${ }^{4}$, se encuentra dentro de las cosas. La relación misma entre las cosas se ha teñido ya de interioridad. De aquí en adelante van a empezar a surgir los intras de Unamuno, que a veces expresarán relaciones entre varias interioridades y a veces la interioridad misma. Inmediatamente (pág. 13) habla Unamuno de la "intra-filosofía"; y unas páginas más adelante volvemos a tropezar con este prefijo intra que tan honda huella ha dejado en el pensamiento español contemporáneo: nos habla Unamuno de lo "intracuantitativo" (pág. 16). Y cuando ya queremos saber hacia dónde apunta este prefijo intra, Unamuno nos lo dice claramente: "Todo tiene entrañas, todo tiene un dentro, incluso la ciencia" (pág. 16). No se da, pues, importancia al fenómeno en este libro de crítica histórica, sino al númeno; estamos ante lo esencial eterno; lo accidental queda reducido a su esencia; la realidad es la íntima, como dirá veinticinco años más tarde. Con estos tres neologismos a base del prefijo intra, y apoyados en la revelación de que todo tiene un dentro, entramos ya en el mundo del alma de las cosas que en adelante Unamuno se lanzará a explorar, haciendo pie en el mundo infantil revivido en la visión de Pachico.

Así, En torno al casticismo, tema del día, aparente discusión de lo fenoménico, resulta ser un libro dirigido a la búsqueda de lo eterno que, a su vez, resulta ser la intrahistoria. Este tema circunstancial, que se discute en España hasta el cansancio por aquellos años ${ }^{\tilde{}}$, y la fría objetividad que domina el estilo del libro, no son más que el punto de partida para llegar a la tesis de la autenticidad del mundo interior.

De aquí en adelante, vemos en esta obra cómo las ideas de Unamuno acerca de España y de la regeneración de todos sus elementos (la crítica va desde la política hasta el teatro) empiezan a girar alrededor de palabras compuestas con el prefijo intra: en las 126 páginas de En torno al casticismo (Ensayos, ed. cit., vol. I) encontramos alrededor de treinta y un intras, de los cuales veintiuno son o el sustan-

\footnotetext{
${ }^{4}$ He aqui la oposición eternidad-tiempo tal como la resuelve Unamuno en esta primera novela suya: "Tendido en la cresta, descansando en el altar gigantesco, bajo el insondable azul infinito, el tiempo, engendrador de cuidados, parécele detenerse ... y y tal fusión de términos y perspectivas del espacio llévale poco a poco, en el silencio allí reinante, a un estado en que se le funden los términos y perspectivas del tiempo..., y en un instante que no pasa, eterno, inmóvil, siente... la hondura del mundo... y oye la canción silenciosa del alma de las cosas... En maravillosa revelación natural penetra entonces en la verdad, verdad de inmensa sencillez: que las puras formas son para el espíritu purificado la esencia misma..." (Paz en la guerra, ed. cit., págs. 333-334).

" Decía Unamuno en 1898: "La moda ahora es lo de la regeneración, moda a que no he podido sustraerme. También yo he echado mi cuarto a espadas" (carta a Ilundain, apud Hernán Benítez, El drama religioso de Unamuno, Buenos Aires, 1949, pág. 278).
} 
tivo intrahistoria o el adjetivo intrahistórico, dos palabras que, desde entonces, Unamuno empleará insistentemente al discutir las cuestiones centrales de su crítica de España. Así, habiendo descubierto que todo tiene entrañas (incluso la ciencia que tan a menudo atacará), Unamuno se va metiendo poco a poco en la historia, dentro de ella, y en lo futuro todo su ensayismo dedicado a temas temporales, a lo externo accidental, será un esfuerzo por encontrar el dentro eterno de los problemas aparentemente corticales de que trate.

Unamuno, pues, empieza su carrera de ensayista mirando hacia lo externo temporal, pero, ya desde este principio, busca en los temas que toca lo esencial eterno. Tratará de España y sus problemas, pero yendo hacia dentro; no atento al estruendo del momento, sino a la paz eterna de la intrahistoria.

Además de los intras, En torno al casticismo abunda en otras expresiones de intimidad. Empieza Unamuno a escudriñar la realidad interior y a hablarnos del "hondón del espíritu" (pág. 84), de la "hondura del alma" (pág. 122), del "hondón oscuro del alma" (pág. 89), de "las entrañas del combate" (pág. 10o); de que es necesario "chapuzarnos en pueblo..., el hondo pueblo, el que vive bajo la historia" (pág. 123), porque, dice, "zambulléndose en el pueblo" se encontrará España (pág. 123), idea "intraísta" central de este libro tan europeizante en apariencia. Estas expresiones -estos sustantivos y verbos tan de Unamuno- y muchas más que no es necesario citar ahora, revelan que Unamuno ha descubierto una realidad interior en todas las cosas y que lo que pretende es "desentrañar la realidad" (pág. 84), llegar a sus entrañas.

Así, Unamuno va creando un lenguaje metafórico que le permite meterse hacia el alma de las cosas, de la intrahistoria, y si bien puede escapársenos el sentido exacto de esta intrahistoria ${ }^{6}$, es porque estamos en el alma ${ }^{7}$, y en el alma la metáfora insinúa pero no define. Por ello, Unamuno, que ha descubierto gradualmente este mundo con la palabra, se empeña en la renovación de metáforas conocidas, como cuando repite el sustantivo entrañas o el verbo desentrañar hasta que los hace suyos y del lector, es decir, nuevos; o como cuando se apoya en la literatura mística y, creando dentro de la tradición, nos habla del "hondón oscuro del alma". Mundo descubierto e insinuado con un lenguaje que Unamuno, ya en esta primera obra importante, va creando y apropiándose y sobre el cual va adquiriendo mayor dominio a medida que avanza su obra.

- Sus contemporáneos, desde luego, no acababan de entender estos conceptos idealistas a los que llamaban "ultratumberías". Cf. la correspondencia con Ilundain, en H. BeNírez, op. cit. A la incomprensión casi general contestaba Unamuno con estas palabras: "Ultratumberías si quieres, aunque más que de cosas de ultratumba hablaba yo de cosas de intra-vida" (Ensayos, I, pág. 548).

7 La intrahistoria es el alma de la historia. 
Ensayos hasta I9oo

Después de En torno al casticismo sigue insistiendo Unamuno en su crítica de lo temporal externo. En muchos de los ensayos sobre temas españoles de circunstancia domina aún el tono didáctico, el tono del joven profesor que expone cuidadosamente la realidad del mundo observada desde fuera. Notamos que han desaparecido aquellos intras en que se apoyaba En torno al casticismo: en más de un centenar de páginas (hablamos siempre de la edición de los Ensayos por la Casa Aguilar) sólo encontramos - una vez- nuestro bien conocido intrahistoria (pág. 165). Habíamos tocado una veta esencial de lo unamunesco y ahora parece que se nos esconde. Pero insistimos y nos vamos dando cuenta de que ni el tono general de los ensayos, ni la ausencia de intras, puede ocultar lo que ya Unamuno ha hecho tan suyo. Empiezan a saltar a la vista, y cada vez con mayor sentido, las expresiones de interioridad. Habla Unamuno de "toda cultura honda y de meollo" (pág. ${ }_{57}$ ), de que el teatro vive en las entrañas del pueblo (pág. 157) -y el pueblo, recordamos, vive en la intrahistoria-, y nos dice que el teatro clásico español era grande porque los autores sabían chapuzarse en las entrañas del pueblo (pág. 158). Surge ahora el verbo ahondar (pág. 159), hermano de aquel zahondar de Paz en la guerra que reaparece cuando dice Unamuno que para lograr otra vez un teatro grande, auténtico, "lo esencial es zahondar en el popularismo" (pág. 160). A propósito de la creación dramática, recomienda con insistencia "chapuzarse en pueblo" (pág. 16o), porque el teatro, como todo lo auténtico, está en el pueblo, alma de la

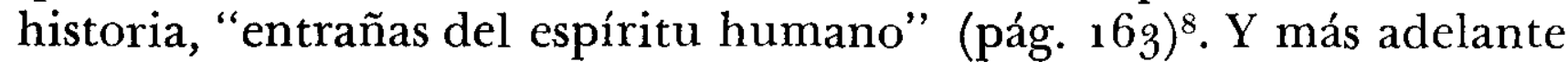
nos recuerda que todo tiene alma, que todo tiene un dentro, cuando dice que hasta los conceptos, tantas veces considerados corticales y fríos, "tienen, como los hombres, vida interior" (pág. 165). Y es que los conceptos son ideas que se forman en el fondo de la mente (pág. $165)$.

Seguimos encontrando expresiones como "el fondo del pueblo" (págs. 165-166), "los abismos de la vida que palpitan debajo de la his-

${ }^{8}$ Es característico de su estilo de esta época que al principio de sus ensayos sobre el teatro español Unamuno no pase de la superficie de la actualidad del tema: empieza siempre por discutir el problema que significan los periódicos, el público, las modas literarias, etc. Poco a poco traspasa esta corteza de lo histórico circunstancial para entrar en sus temas interiorizantes de la tradición eterna, del alma del pueblo, del espíritu de la intrahistoria nacional, etc. Aquí, como en todo, empieza Unamuno por lo más fácil, por lo que tiene más a mano en su espacio y en su tiempo; pero no tardamos en darnos cuenta de que ataca estos problemas de actualidad, externos, hacia adentro, siempre en busca de la eternidad en que se apoya el tiempo ("Es la guerra a la paz lo que a la eternidad el tiempo: su forma pasajera", había dicho en Paz en la guerra, ed. cit., pág. 335). Esto es ya en él el proceso de "eternizar la momentaneidad" que veremos al final de este trabajo. 
toria" (pág. 169); y para decirnos que hemos llegado al final del problema de la regeneración del teatro español afirma que "hemos llegado al último fondo del problema" (pág. 171), y ya esta frase común, el fondo del problema, recibe un nuevo sentido en el conjunto del pensamiento de Unamuno: es de verdad el fondo del problema, porque la solución definitiva es "ahondar [en] los elementos de nuestra dramaturgia y estética tradicional" (pág. 173); es de verdad el fondo del problema porque estamos dentro, en el alma de la historia.

Estamos en "las aguas profundas de las entrañas insondables del espíritu" (pág. 218). Y seguimos con el tema central de En torno al casticismo: "el pueblo..., soñando su vida por debajo de la Historia, anuda la oscura cadena de sus existencias en el seno de la eternidad" (pág. 221). Va a pasar Unamuno de los problemas de España (que, desde luego, le preocuparán siempre) a los del hombre concreto; el alma de la persona va a sustituir a la colectiva; el alma del hombre a la de la Historia ${ }^{9}$; pero antes de cerrar este fecundo período de crítica intrahistórica, resume su actitud ante la historia y el pueblo en La vida es sueño: "Esclavos del tiempo, nos esforzamos por dar realidad de presente al porvenir y al pasado, y no intuímos lo eterno por buscarlo en el tiempo, en la Historia, y no dentro de él... Desgraciado pueblo, ¿quién le librará de esta historia de muerte?" 10

\section{¡Adentro!}

Ahora, con el ensayo ;Adentro!, la interioridad de la obra de Unamuno adquiere un doble aspecto. Primero, hace del hombre la

- Como veremos, Unamuno nunca dejó de preocuparse por su circunstancia histórica ni eejó en su empeño de darle un sentido interior y eterno; pero a partir del ensayo ;Adentro!, que comentaremos en seguida, es cada vez más patente su preocupación por el individuo y empiezan a surgir esos ensayos, parte autoanálisis, parte confesión personal, en que Unamuno va "zahondando" por el alma del hombre, por su propia alma. En cste periodo de su madurez es cuando aparecen sus nivolas, que, en oposición a Paz en la guerra ("relato del más grande y fecundo episodio nacional", Prólogo a la $2^{\text {a }}$ edición), relatan episodios de almas individuales; de esta personalización de sus temas nace Del sentimiento trágico, y también a partir de este nuevo enfoque (que, insisto, nunca desvía totalmente a Unamuno de su preocupación por los temas nacionales) es cuando Unamuno empieza a dar a conocer su poesía, su obra más personal (publica su primer tomo de versos en 1907 , en los años que van de la Vida de Don Quijote y Sancho a Del sentimiento; en los años en que afirma su madurez).

${ }_{10}$ Ya antes, en su famoso artículo ¡Muera don Quijote! (1898), había atacado a la Historia con una violencia tal vez nunca superada en el resto de su obra: “¡Ojalá en España se pudiese olvidar la historia nacional! .. ;Continuar la historia de España!. . . Io que hay que hacer es acabar con ella, para empezar la del pueblo español. iTerrible esclavitud la de los pueblos guiados por su mezquina imagen en la historia, superficie y nada más de la vida!.. Preocuparse por sobrevivir en la historia estorba el subsistir en la eternidad..." (De esto y aquello, Buenos Aires, 1951, vol. II, págs. 81-82). 
realidad última y centro del universo ${ }^{11}$, y, segundo, se mete en el alma de este hombre que siempre resulta ser Unamuno mismo ${ }^{12}$. En esta carta-consejo que es el ensayo ;Adentro! recomienda Unamuno a su corresponsal: "Avanza, pues, en las honduras de tu espíritu ..." (pág. 225), y le incita a que busque la libertad que "es ideal e interior, es la esencia misma de nuestro posesionamiento del mundo, al interiorizarlo" (pág. 227). Sus últimos consejos son: "Deja eso de adelante y atrás, arriba y abajo, a progresistas y retrógrados, ascendentes y descendentes, que se mueven en el espacio exterior tan sólo, y busca el otro, tu ámbito interior, el ideal, el de tu alma ... En vez de decir, pues, jadelante!, o jarriba!, di: ¡adentro!" (pág. 231). Y el ensayo termina con estas palabras: "... tienes que hacerte Universo, buscándolo dentro de ti. ¡Adentro!” (pág. 232).

\section{Ensayos posteriores}

Así, al entrar a su madurez, resuelve Unamuno la dualidad del mundo escogiendo entre "lo uno y lo otro": todo lo interior es auténtico y todo lo exterior falso. Y siguen abundantísimas las expresiones que apuntan hacia la vida interior hasta llegar, en 1920, a la teoría de la realidad que hemos visto enunciada, al principio de estas páginas, en el Prólogo a Tres novelas ejemplares y un prólogo ${ }^{13}$.

De este oponer lo interior a lo externo sưrgen las abundantes parejas de contrarios entre los que Unamuno escoge con un criterio que destruye toda posible unidad en contradicción: vida auténtica y vida inauténtica; mundo de dentro y mundo de fuera; intramundo

11 Dice concretamente en este ensayo: “imi centro está en mí!” (Ensayos, I, pág. 224). Ya antes (Ensayos, I, pág. 22) había dicho: "El hombre, esto es lo que hemos de buscar en nuestra alma”. Y más adelante (pág. 59): “¡un hombre!, un hombre es la más rica idea, llena de nimbos y de penumbras y de fecundos misterios"; pero en la primera época de su vida, en que dice estas palabras, su preocupación central era España y su Historia e intrahistoria; en la madurę, su preocupación central será cl hombre, el de carne y hueso, al que, por cierto, ya se refería en el ensayo La ideocracia (Ensayos, I, pág. 224). En realidad Unamuno siempre alternó su preocupación por la intrahistoria con su preocupación por la persona, aunque subrayando más la una o la otra en cada uno de los dos períodos que aquí distingo.

12 Justificaba Unamuno su "egoísmo" con estas palabras: "Permitidme que hable de mí mismo...; soy el hombre que tengo más a mano, como decía mi paisano Trueba" (Ensayos, I, pág. 517).

${ }^{13}$ Para no hacer una enumeración excesivamente detallada y enojosa de las expresiones "interiorizantes" que aparecen en la extensísima obra de Unamuno, daremos sólo unos cuantos ejemplos que aparecen a lo largo de varios años: "La verdad es algo más íntimo que la concordancia lógica de dos conceptos, algo más entrañable que la ecuación del intelecto con la cosa..., y vivir verdad es más hondo que tener razón" (pág. 238); "verdad es aquello que intimas y haces tuyo" (pág. 239); la fe consiste en trabajar "en el tiempo para la eternidad, sin correr tras el inmediato efecto exterior; trabajar no para la Historia, sino 
у mundo; entrañas y extrañas; substancial y accidental; personalidad e individualidad; cultura y civilización; intrahistoria e historia; intracasticismo y casticismo; vida intima y vida de la historia; silencio y ruido; paz y guerra; eternidad y tiempo; espiritu y materia; alma y cuerpo; espiritu y razón; hondo y cortical; poesia y ciencia; locura y cordura; vida agónica y marasmo; duda y fe; heterodoxia y ortodoxia.

Con clarísima conciencia va Unamuno eliminando de su obra toda posibilidad de contradicción en la unidad al escoger estos contrarios y oponerlos los unos a los otros como conceptos antagónicos separados entre sí. De esta manera, la agonía no es más que la lucha de lo uno contra lo otro sin unidad contradictoria. Así, vemos que escoge la vida "auténtica", que es la del mundo de dentro, la del intramundo, la de las entrañas, lo sustancial, y la opone a la vida del mundo de fuera, de lo accidental. Busca la personalidad (lo íntimo) e insiste en que no hay que confundirla con la individualidad (lo que el mundo ve de nosotros). En el plano histórico-social la oposición equivalente es entre cultura y civilización; y como complemento de esto, aboga por la intrahistoria frente a la historia y lucha contra el casticismo - lo circunstancial histórico- porque él es, dice, "intracastizo". Así, vemos la vida íntima oponiéndose a la vida de la historia, el silencio al ruido, la paz a la guerra. Toda esta vida de lo interior que busca Unamuno es eternidad frente a tiempo, espíritu frente a materia, alma frente a cuerpo; espíritu, también, frente a intelecto o razón, de donde la idea de que "vivir verdad es más hondo que tener razón”, porque tener razón es cuestión de lógica y la lógica es antivital (de donde la superioridad de la poesía sobre la ciencia y la filosofía), y tener razón es, también, cuestión social, de sentido

para la eternidad" (pág. 246); en la pág. 250 habla del Dios intrarracional; "la Historia, la condenada Historia, nos oprime y ahoga, impidiendo que nos bañemos en las aguas vivas de la humanidad eterna, la que palpita en hechos permanentes bajo los mudables sucesos históricos" (pág. 269); “debajo de esa historia de sucesos fugaces, historia bullanguera, hay otra profunda historia de hechos permanentes" (pág. 273); "al hundirse a su propia pesadumbre las civilizaciones exteriores, el mundo de las instituciones y monumentos del ambiente social, libertan las culturas interiores" (pág. 293); "la vida íntima ..., la subhistórica..., lo que podemos llamar subconciencia nacional..." (pág. 320); y cuando Unamuno quiere decir que algo tiene un gran valor, un valor auténtico, emplea los adjetivos hondo y profundo: “Profundo revolucionario Duns Escoto!" (pág. 324); o bien, "[en Goethe] cupieron la más honda comprensión del paganismo con una comprensión hondísima del cristianismo" (pág. 508). Otras expresiones: "Dice Machado que ansía luz. Es que se está haciendo la luz en sus entrañas, o mejor, en sus sotọentrañas espirituales" (pág. 532); habla de "intramundo" (págs. 542-543), y nos vuelve a hablar de las "honduras del espíritu" (pág. 607) y de la "fe honda" (pág. 624), etc. Estas expresiones van de 1900 a $190_{5}$, fecha en que llega a su madurez con la Vida de Don Quijote y Sancho. 
común, exterior al hombre mismo (de donde su defensa de la locura frente a la cordura, que no es más que lo razonable social común). $Y$ por último, su insistencia en que frente a la muerte que significa el marasmo social y la fe del carbonero, lo profundo y auténtico, lo íntimo y personal de la vida agónica es la duda: heterodoxia es vida, ortodoxia es muerte en la fe muerta.

En el centro de todo esto, y activos en la lucha por la interioridad, encontramos los verbos tan de Unamuno: ahondar y zahondar, que se oponen a flanear; y el verbo desentrañar, que se opone a repetir lo olvidado de puro sabido. Verbos que llevan a otros fundamentales en Unamuno: despertar y agonizar, en oposición a dormir y creer según el Catecismo.

\section{Última época: "Cómo se hace una novela"}

Pero hasta aquí, empujado por su pasión de afirmar y negar, empujado por la necesidad elemental de escoger, Unamuno había venido simplificando la realidad al quedarse con lo interior y rechazar lo externo. Porque, como en seguida veremos, el mundo es dos en unidad contradictoria y no dos en dualidad de contrarios entre los que se puede escoger para enfrentar los unos a los otros y hacer con ellos la agonía; y el hombre - unidad de alma y cuerpo, espíritu e intelecto, corazón y cabeza-, si tiene una realidad interior, también vive en el mundo; participa de lo eterno y pertenece al tiempo. Ya Unamuno había dicho algunas veces: "Llevo dentro de mí dos hombres" 14 , y en las palabras que anteceden a las que citamos al principio de este trabajo había tenido que admitir que "este hombre que podríamos llamar, al modo kantiano, numénico,...tiene que vivir en un mundo fenoménico, aparencial, racional, en el mundo de los llamados realistas"15. A pesar del dejo despectivo con que Unamuno se refiere a este mundo "fenoménico", la verdad ahí queda: el hombre está entregado a la contradicción porque, como él mismo había dicho ya en las páginas de En torno al casticismo, el verdadero misterio del pecado original es "la condenación de la idea al tiempo y al espacio, al cuerpo"16. Y ya en Del sentimiento trágico (1912) Unamuno había aceptado de lleno la contradicción y había expuesto con lujo de detalles una de las formas de la agonía, la más importante, que esa contradicción produce ${ }^{1 \tau}$. Pero en el resto de su obra tiende

${ }^{14}$ Cf. Ensayos, I, pág. 462; en otra ocasión, en el Prólogo a un libro de poesías de su amigo Arzadun -Bilbao, 1897-, decía que "es de saber que hay en nosotros dos hombres" (citado por SÁnchez Barbudo, "El misterio de la personalidad de Unamuno”, $R U B A$, XLVI, 1950, págs. 213-214, nota 10)

${ }_{15}$ Tres novelas ejemplares y un prólogo, $2^{n}$ ed., Madrid s. f., pág. 19.

${ }^{10}$ Ensayos, I, pág. 13.

${ }_{17}$ Se trata de la lucha entre el corazón y la cabeza que nace de que "este yo concreto, circunscrito, de carne y hueso, que sufre de mal de muelas y no encuen- 
a soslayar el problema porque no se entrega a la contradicción sino que escoge entre los contrarios, presentando la agonía como esfuerzo por aferrarse a lo numénico eterno interior y rechazar lo fenoménico temporal, siendo la verdad que la agonía consiste en aceptar los contrarios en unidad de guerra.

Por lo general, Unamuno se pronuncia por uno de los contrarios evitando con ello la verdadera agonía, pero algunas veces ya se había visto obligado a presentar esta verdadera agonía, aunque en forma más o menos teórica. La primera expresión importante de esta íntima contradicción que es el hombre la encontramos en las últimas palabras de Paz en la guerra con las que Pachico acepta la necesidad ${ }^{18}$ de salir de la paz del alma a la guerra del mundo ${ }^{19}$. Esta idea aparece de vez en cuando en otras obras suyas ${ }^{20}$, pero Unamuno evita la verdadera contradicción cuando, aun teniendo conciencia de la "unidad" antagónica de los dos mundos (interior y externo), insiste en buscar sólo por el mundo del alma y aconseja penetrar ;Adentro!, despreciando lo circunstancial y la historia.

tra soportable la vida si la muerte es la aniquilación de la conciencia personal" (Del sentimiento trágico de la vida, $5^{\sharp}$ ed., Madrid, 1938, pág. 31) quiere eternizarse y ser Dios (pág. 41), pero sin dejar de ser él mismo, "sin dejar de ser el yo que ahora os digo esto" (pág. 47). La inmortalidad que pide el corazón, en lucha con la cabeza, encierra en sí toda la contradicción del hombre cuya existencia imperfecta aspira a la perfección, pero sin dejar de ser sí misma: Unamuno le pide a la muerte alma $y$ cuerpo, eternidad $y$ tiempo, porque "la inmortalidad que apetecemos es una inmortalidad fenoménica, es una continuación de esta vida" (pág. 85). ¿Fenoménica la continuación de esta vida? Sí, porque a pesar de que el hombre es la intimidad del alma que buscaba y encontró Unamuno, es hombre precisamente porque vive en el mundo y no sólo es como se siente por dentro, sino como los otros lo ven (cf. las últimas páginas de este trabajo), es fenómeno, en la mejor acepción kantiana de la palabra. Aquí ya los contrarios van unidos en inseparable contradicción. "Y hemos llegado al fondo del abismo" (pág. 121), al abismo en que, ya no teóricamente, sino como vivencia radical, caerá Unamuno en sus últimos años.

18 Digo "necesidad" porque, para Unamuno, la presencia del alma en el tiempo no es acto de libertad, sino tragedia inevitable. Además, para él, todo acto humano de libertad es producto de una necesidad: "La libertad es la conciencia de la necesidad" (Ensayos, I, pág. 314).

19 Dice Unamuno cuando Pachico baja del monte después de haber descubierto el alma de las cosas: "Así es como allí arriba, vencido el tiempo, toma gusto a las cosas eternas, ganando bríos para lanzarse al torrente incoercible del progreso, en que rueda lo pasajero sobre lo permanente" (ed. cit., pág. 335).

${ }^{20} \mathrm{El}$ ensayo Civilización y cultura (Ensayos, I, págs. 289 y sigs.) empieza con estas palabras: "Hay un ambiente exterior, el mundo de los fenómenos sensibles, que nos envuelve y sustenta, y un ambiente interior ... Nadie puede decir dónde acaba el uno y el otro empieza..." Pero, aunque, como en tantos otros sitios, Unamuno admite aquí la real realidad de los dos mundos, el ensayo todo es una defensa más del mundo interior que acaba por "tragarse" el mundo de fuera, hasta que la única realidad es la del alma, la interior, la eterna. 
$\mathrm{Y}$, paradójicamente, es un suceso fenoménico ${ }^{21}$, accidental, histórico, el que lanza a Unamuno a las más profundas complejidades de la contradictoria unidad eternidad-tiempo, interioridad-exterioridad. La vivencia radical del problema empieza, para siempre, en 1924, cuando sufre el destierro bajo la dictadura de Primo de Rivera ${ }^{22}$.

En esos años, y aún después, ya de regreso en España, busca Unamuno dentro de sí como nunca, y surge de ello su obra más compleja, la que más se debate en la contradicción íntima del hombre. Todo empieza cuando Unamuno se pregunta si en su destierro no estará acaso representando el papel de desterrado; representando un papel, es decir, haciendo teatro, siendo hipócrita, poniéndole una máscara a su "verdadera" realidad interior y entregándose a la Historia para adquirir y dejar nombre en ella: "Ahora hago el papel de proscrito. Hasta el descuidado desaliño de mi persona depende del papel que represento. ¿Es que represento una comedia hasta para los míos?”23

Con esta preocupación entra Unamuno de lleno en lo que llamaba "el misterio de la personalidad": ¿Soy yo el que los otros ven o el que me siento por dentro? ¿Númeno o fenómeno? Es el viejo problema "personalidad-individualidad" 24 que surge ahora como viven-

${ }^{21}$ Suceso, no hecho; los hechos quedan, los sucesos pasan con la historia, como todo lo fenoménico. (Cf. Obras completas, Madrid, 1950, vol. IV, pág. 941).

${ }^{22}$ Esta vivencia empieza para siempre, hacia el público, en esta fecha. Ya antes palpitaba en el interior de Unamuno como algo confesable sólo a sí mismo o a los amigos. Véase, por ejemplo, lo que le decía a Clarín en una carta de 1900; Unamuno se analiza a sí mismo en tercera persona, y dice: "Unamuno es una víctima de sí mismo, un heautontimoroumenos. Pásase la vida luchando para ser como no es y sin conseguirlo... Cuando Unamuno dice y repite que hay que vivir para la eternidad y para la historia es porque sufre de querer vivir en la historia, y aun cuando su parte mejor le muestra lo vano de ella, su parte peor le tira". Unamuno, pues, sintió siempre el peso de la historia, como es natural que lo sienta todo hombre, pero pretendió escondérselo a su público la mayor parte del tiempo. Se defendió siempre de sí mismo, y también frente a Clarín se defendía: "Pero sufre - sigue diciendo Unamuno- de que le atribuyan a ese solo móvil, el ansia de notoriedad y fama, cambios y actitudes que le arrancan del corazón" (citado por M. García Blanco, en $A O$, II, 1952, págs. 121-122). Asóciense estas preocupaciones de 1900 con los sentimientos de culpa que, como veremos, le produce su farsa "histórica" de 1924.

${ }^{23}$ Obras completas (en adelante $O$. C.), IV, pág. $95^{6}$.

${ }^{24}$ Cf. Ensayos, I, págs, $425-427,434,504,515,836-837,847$, etc. La preocupación por la diferencia entre un "yo" profundo y un "yo" superficial viene, pues, de lejos. Algo de ello encontramos también en Paz en la guerra y en algunas páginas de En torno al casticismo (por ejemplo cuando dice que, generalmente, tomamos por nuestra personalidad íntima el yo que de ella nos refleja el mundo, Ensayos, I, pág. 122). Encontramos también una presentación del conflicto entre los dos "yo", entre los dos mundos, del conflicto entre la realidad interior y la "farsa" o "papel" exterior que ven los otros, en el Prólogo a las Tres novelas ejemplares y un prólogo. Veamos algunos de estos ejemplos; decía Unamuno en 19o6: Hay "un yo profundo, radical, permanente... y otro yo superficial, pegadizo, pasajero" (Ensayos, I, pág. 847) ; y acerca de la falsedad del yo exterior 
cia radical sufrida a fondo. Aquí, por primera vez en muchos años, Unamuno se pregunta de verdad si el mundo de fuera no será tan real e importante como el mundo interior que había descubierto y defendido por tanto tiempo. Ante la inminente presencia de su propia farsa, el problema, que antes era casi puramente teórico, pasa a ser ahora el angustioso centro de su vida y obra última. Empujado por este conflicto, y para confesarlo y resolverlo, escribió Cómo se hace una novela ${ }^{25}$.

Si En torno al casticismo (1895) desdeñaba la historia para lanzarse en pos de la realidad de la intrahistoria, ahora, treinta años después, Cómo se hace una novela es un libro de honda obsesión por la historia; Unamuno admite ya como necesario y real el mundo al que antes llamaba fenoménico y aparencial; ante la presencia de "este espantoso presente histórico" (O. C., IV, pág. 937) que lo atropella como nunca antes, Unamuno ya no puede rechazar la "posibilidad de los espantos" (ibid.) que es la historia para refugiarse y hallar su verdad sólo en la eternidad de la intrahistoria. A su alrededor, y metiéndose hasta su alma, todo es candente actualidad inevitable y real. Y desde las primeras páginas del libro entramos de lleno en la contradicción que es el hombre: "Héteme aquí ante estas blancas páginas -blancas como el negro porvenir: ¡terrible blancura!- buscando retener el tiempo que pasa, fijar el huidero hoy..." (ibid.). En este libro trata Unamuno de resolver en síntesis la contradicción eternidad-tiempo, interioridad-exterioridad, trata de fijar el "huidero hoy", pero, de hecho, el resultado no es una síntesis armoniosa ${ }^{26}$, sino la presentación angustiada de la insoluble contradicción agónica

decía unas páginas antes: "Los diversos conceptos que de cada uno de nosotros se forjan los prójimos que nos tratan vienen a caer sobre nuestro espíritu y acaban por envolverlo en una especie de caparazón... Antes de hacer o decir algo reflexiona [uno] si es lo que de él esperaban los demás, y para seguir siendo como los demás le creen se hace traición a sí mismo: es insincero" (ibid., págs.

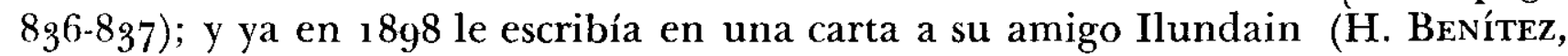
$o p$. cit., pág. 261) que "la perdición de todo el que se muestra en público es que en torno a su sujeto íntimo, el que se desarrolla desde dentro a fuera a partir del eterno núcleo, nos forma el mundo otro sujeto depositándonos capas de acarreo, un sujeto constituído de fuera a dentro, un caparazón que acaba por enquistar al íntimo. ¿Qué admirablemente describió San Pablo la lucha de estos sujetos, de estos dos hombres que llevamos todos!" Ya en 1898 , pues, era ésta una preocupación central para Unamuno, y ya en 1898 menciona a San Pablo, quien le servirá otra vez de guía al escribir Cómo se hace una novela, según veremos, en 1925 .

${ }^{25}$ Escrito en París, en español, en 1925; publicado en francés en 1926; traducido al español con una Continuación, en 1927 , en Hendaya. Debo decir aquí que aprovecho en este trabajo materiales del artículo ya citado de SÁnchez BARBUDo, con quien, por otra parte, y como se verá más adelante, no estoy de acuerdo en la interpretación de este "problema de la personalidad" en Unamuno.

${ }^{26}$ Siempre había querido Unamuno lograr la "integración de los contrarios". En esta obra los integra, sí, pero en lucha, no en armonía. 
que es el hombre; esta contradicción late como vivencia radical en el centro de las paradojas que, a la manera heracliteana (o quevediana), se suceden unas tras otras en Cómo se hace una novela: "La historia, lo único vivo, es el presente eterno, el momento huidero que se queda pasando, que pasa quedándose..." (op. cit., pág. 912). La aparente síntesis no es más que el eco engañoso de la agonía de Unamuno, que se debate como nunca entre su yo interior y su presencia en la historia. El momento histórico lo tiene prisionero y obsesionado, y su preocupación central es armonizarlo con la eternidad. Pero sólo logra reflejar la agonía. Ya para acabar el libro, cuando escribe la Continuación en Hendaya (1927), confiesa: "Sigo pensando... en la historia" (op. cit., pág. 983 ).

$\mathrm{Y}$ es que ahora Unamuno es más personaje histórico que nunca. Si siempre había sido figura pública, ahora es la primera figura española: ante Francia y ante el público español ha llegado a simbolizar la tragedia histórica de España bajo la dictadura y la esperanza, también histórica, de un cambio. El Unamuno que solía refugiarse en la paz del campo y de Salamanca para huir del bullicio del tiempo y de la ciudad, ve ahora asediada su paz interior por los sucesos del momento. Y a pesar de que todos sus amigos y lectores saben de sus preocupaciones íntimas y lo tratan como símbolo del espíritu español eterno, su figura crece inevitablemente hacia fuera, hacia la consideración circunstancial de sus contemporáneos, hacia la Historia, transformando su paz interior en una honda preocupación por los sucesos de actualidad. "IVivir en la historia y vivir la historia!" (pág. 941) es su preocupación obligada de estos años, y es el tema de Cómo se hace una novela. Desde que llega a París y se ve acogido como representante de España, le vuelve a asaltar la duda que había resuelto, de manera más o menos teórica, en su vida y obra anterior a 1924: “ ¿No estaré acaso a punto de sacrificar mi yo intimo, divino, el que soy en Dios, el que debo ser, al otro, al yo histórico, al que se mueve en su historia y con su historia?" (pág. 955).

"El que debo ser": insiste Unamuno en negar lo circunstancial externo. Pero el torbellino de la historia lo arrastra, y viene, por necesidad, la respuesta categórica: "Es que si no hago mi leyenda me muero del todo" (ibid.). Sin embargo, la duda sigue en pie. No en vano había afirmado la interioridad del mundo durante tantos años. Pero a la nueva duda sigue siempre la nueva y total aceptación de la historia: “¿Es que represento una comedia hasta para los míos? ¡Pero no! es que mi vida y mi verdad son mi papel”. “¿Hipócrita? ¡No! Mi papel es mi verdad y debo vivir mi verdad que es mi vida" (pág. 956). ${ }^{27}$ Unamuno acepta aquí la vida interior y la vida de la historia

${ }^{27}$ Obsesionado por demostrar el ateísmo de Unamuno, Sánchez Barbudo (loc. cit.) insiste en que Unamuno sí estaba representando una farsa durante estos años; que representaba un papel y se engañaba huyendo de su verdadera 
en juego agónico. ¿Hipócrita? No, porque mi farsa y mi realidad íntima forman, agonizando, mi yo entero de Miguel de Unamuno. No es que el mundo de fuera sea igual al de dentro, es que los dos son una indestructible unidad contradictoria; los dos en contradicción me hacen hombre concreto, de alma y cuerpo, de eternidad y tiempo, de historia e intrahistoria, imperfecto y en guerra conmigo mismo porque "el verdadero pecado original es la condenación de la idea al tiempo". Y así, en una violenta paradoja que a la vez que lo defiende de la acusación de farsante lo lanza a toda la complejidad del hombre y del mundo, dice Unamuno que "hay una leyenda de la realidad que es la substancia, la íntima realidad de la realidad misma" (pág. 941); y cambia radicalmente su vieja postura al decir que "la esencia.de un individuo y de un pueblo es su historia" (ibid.).

Hasta aquí Unamuno venía creyendo que una realidad (la interior) era verdadera, y otra (la externa) falsa; ahora cae en la cuenta de que la realidad exterior (historia o novela o leyenda o farsa: lo que ven los otros) es tan verdad como la interior, puesto que en ella vive y con ella morirá: "Esta leyenda, esta historia, me devora, y cuando ella se acabe me acabaré yo con ella". "El Unamuno de mi leyenda, de mi novela, este Unamuno me da vida y muerte, me crea y me destruye, me sostiene y me ahoga. Es mi agonía" (pág. 942).

Otra vez la expresión paradójica, la unión antagónica de los contrarios, no la síntesis armoniosa. De ahí la precisión con que Unamuno emplea una vez más la palabra agonía. Porque agonía es lucha. Y lucha de contrarios: $m i$ vida interior y $m i$ vida exterior en pugna hacen $m i$ agonía, me hacen. Eliminar cualquiera de estas dos realidades es mutilar la realidad. De aquí la paradoja "me da vida y

realidad porque en su interior había tropezado con la nada. Para huir de la nada, Unamuno se deja arrastrar por la corriente de la historia y representa el "papel" de exilado. Así, haciendo farsa, entretenía su vaciedad y escondía su ateísmo íntimo. Dejando a un lado el problema del ateísmo de Unamuno, yo creo que debemos ver esta preocupación por la Historia como la entrada definitiva de Unamuno en su vivencia más radical desde la cual admite para siempre la existencia real y fundamental de los dos mundos en lucha. En estos años, y con este libro, llega Unamuno a la total madurez de su pensamiento y vida y a la lógica desembocadura de su concepto de la agonía y de la contradicción. Al fijarse sólo en el ateísmo de Unamuno (siempre problemático, por otra parte), Sánchez Barbudo pierde de vista que Unamuno se encuentra ante (dentro de) una situación vital única que le enfrenta radicalmente con la historia y el problema del hombre exterior en lucha con el interior. El ver en todo esto nada más que una manera de hacerse trampa a sí mismo es sacar a Unamuno del torbellino histórico-nacional-político que lo arrastró por aquellos años ha. ciendo que salieran a flote para siempre todos los problemas sobre la interioridad y la exterioridad, sobre la historia y la intrahistoria, el hombre de dentro y el de fuera, que durante tantos años había vislumbrado teóricamente y almacenado hasta el momento de la definitiva crisis, vivencia, que significó para él el destierro. 
muerte, me crea y me destruye": la historia destruye mi simplicidad interior pero con ello me crea como todo, como hombre concreto, no ya de carne y hueso, sino de alma y carne. Y no sólo esto, sino que, en verdad, yo soy mi leyenda, puesto que como hombre (no Dios, ni ángel) vivo en el mundo, que es tiempo e historia. La pregunta "¿seré como me creo o como se me cree?" llega a perder su sentido ante el hecho ineludible de que cuando mi leyenda se acabe "me acabaré yo con ella". Por esto, escrito para resolver en lo posible el problema planteado por su vivencia del exilio, Cómo se hace una novela es un libro dado al mundo bajo la obsesión de la actualidad. Ante su importancia histórica, adquirida de la noche a la mañana, Unamuno se da cuenta de la importancia de "vivir en la historia y vivir la historia, [de] hacerme en la historia" (pág. 942), porque la historia me destruye, sí, pero a la vez me hace. El hombre es, sin duda, el que se siente por dentro, pero también el que los otros ven. $\mathrm{Y}$ así, resulta ahora que "todo hombre, verdaderamente hombre, es hijo de una leyenda, escrita u oral. Y no más que leyenda, o sea novela" (pág. 980). O sea historia, circunstancia, exterioridad, mundo fenoménico.

Y Jugo de la Raza, el personaje de Cómo se hace una novela, no es un hombre "verdaderamente hombre", "porque no vive ya más que en sí mismo, en el pobre yo de bajo la historia, en el hombre triste que no se ha hecho novela. Y por eso le gustan las novelas" (pág. 944). Le gustan las novelas porque novela es leyenda y es historia, es la parte exterior de la vida sin la cual la realidad queda mutilada. Y Jugo de la Raza encuentra un día, en París, una novela que le obsesiona, y se entrega a ella hasta que llega el momento en que "el pobre... no podía vivir sin el libro, sin aquel libro; su vida, su existencia íntima, su realidad, su verdadera realidad estaba ya definitiva e irrevocablemente unida a la del personaje de la novela" (pág. 945), es decir, a la historia. Y así, la pregunta "¿seré como me creo o como se me cree?" no tiene más que una respuesta: de las dos maneras unidas en contradicción: “... ¿un hombre histórico? ¿Un hombre de verdad? ¿Un actor del drama de la vida? ¿Un sujeto de novela? Éste lleva las entrañas en la cara. O dicho de otro modo, su entraña -intranea-, lo de dentro, es su extraña - extranea-, lo de fuera; su forma es su fondo..." (pág. 981). Ahora sabe Unamuno que no se puede escoger entre lo uno y lo otro. Queda admitida la paradoja del hombre, Unamuno se ve obligado a confesar que "lo que parece realidad extraescénica es comedia de comedia, novela de novela... el noúmeno inventado por Kant es de lo más fenomenal que puede darse, y la substancia de lo más formal. El fondo de una cosa es su superficie" (pág. 965).

Jugo de la Raza trata aún de evadirse de esta verdad: "Mi Jugo se dejaría al cabo del libro, renunciaría al libro fatídico.... En sus 
correrías por los mundos de Dios para escapar a la fatídica lectura iría a dar a su tierra natal, a la de su niñez, y en ella se encontraría con su niñez misma, con su niñez eterna, con aquella edad en que aún no sabía leer, en que todavía no era hombre de libro. Y en esa niñez encontraría su hombre interior..." (pág. 972). En varias de las torturadas páginas de Cómo se hace una novela palpita esta añoranza de vida de paz, interior y eterna; pero no puede ser: el hombre está entregado a la historia y Jugo de la Raza no logra evadirse hacia su mundo infantil y tiene que volver siempre al libro, porque "el hombre de dentro, el intra-hombre, cuando se hace lector, hácese por lo mismo autor, o sea actor ..." (pág. 976). Mundo de dentro y mundo de fuera quedan ya en permanente interacción contradictoria.

Así, obligado por la crisis del exilio, Unamuno abandona su visión simplista del mundo y del hombre, y si antes su pensamiento marchaba por "afirmación alternativa de los contrarios" 28 , ahora la afirmación no es ya alternativa sino simultánea, fundida en la unidad dinámica de la paradoja. Las parejas de contrarios se aceptan ya en su interacción agónica ${ }^{29}$. Por eso, en 1934 , terminada su obra y casi terminada su vida, en plena madurez y posesión de su pensamiento, pudo rectificar su viejo concepto de historia e intrahistoria: "Lo que llamé la intra-historia es la historia misma, su entraña" 30 . Entraña y extraña son ya la misma unidad en agonía; en agonía que es vida, no en síntesis armoniosa, que sería muerte.

A lo largo de su vida Unamuno había venido pugnando por escoger entre la historia y la intra-historia, el alma y el cuerpo, " $i$ Ser mirado, ser admirado y dejar nombre!"31 y ser eterno; entre vivir en la paz o en la guerra. Ahora llega a su posición definitiva, a lo que es su aportación original, en cuanto vivencia, al pensamiento moderno: la lucha sin solución de los contrarios: "Y no es otro el arte de la vida en la historia” (op. cit., pág. 982). "AAy, que no hay paz sin guerra!" (pág. 984).

Carlos Blanco Aguinaga

El Colegio de México.

${ }^{28}$ Cf. En torno al casticismo (Ensayos, I, pág. 7).

${ }^{20}$ Unamuno siempre usó paradojas, pero nunca tantas ni tan auténticas como en este libro. Algunos ejemplos: "La acción es contemplativa, la contemplación es activa; la política es novelesca y la novela es política” (O. C., pág. 976); “...una novela de eternidad histórica” (pág. 971); “¿He de repetir mi expresión favorita la eternización de la momentaneidad?” (pág. 938).

${ }^{30}$ Citado por Sánchez Barbudo, art. cit., págs. $214^{-2} 15$.

${ }^{31}$ Citado ibid, págs. 249-250. 